\title{
The Countermeasures of Intelligent Development of China's Tourism Public Service under the Context of "the Belt and Road"
}

\author{
Tong Haonan ${ }^{a}$; Li Shengjie; Chen Xiaojie; Liu Qian; Wang Jingwen; Chu Deping ${ }^{\mathrm{b}}$ \\ School of Tourism \\ Fujian Normal University \\ Fuzhou, Fujian 350108 \\ a347161882@qq.com \\ b chudeping2000@126.com
}

\begin{abstract}
China has gradually realized a his toric leap from a tourism-scarce developing country to a large tourism country. This paper analyzes the current construction situation of China's tourism public service system. Combining the "the Belt and Road" initiative, the paper believes that the construction of China's tourism public service system includes tourism information consultation service system, convenient senvice system of tourism transportation, tourism security guarantee service system, convenient and beneficial service system for touris ts and tourism adminis trative service system. Furthermore, it proposes the countermeasures of intelligent development of China's tourism public service system from the aspects of tourism information consultation service, convenient service of tourism transportation, tourism security guarantee service, convenient and beneficial service for tourists and tourism adminis trative service.
\end{abstract}

Keywords-tourism public service; tourism public service system; intelligent; smart city; "the Belt and Road" initiative

\section{OVERVIEW OF THE DeVElopment of TOURISM Public} SERVICE

In the 40 years since China's reform and opening up, it has achieved a historic leap from a tourism-scarce country to a large tourism country. Under the diplomatic layout of "allround, multi-level and three-dimensional", the international status of China has steadily improved and the openness to the outside world has gradually deepened. In 2017, the number of inbound tourists in China was 139 million, an increase of $0.8 \%$ over the same period of last year, among which the year-onyear growth rate of entry market was 3.6\%. The countries along "the Belt and Road" promoted exchanges significantly; in 2017, the inbound tourism foreign exchange income was 123.417 billion US dollars, an increase of $2.9 \%$ on the previous year, and it continued to maintain a good momentum of steady growth [1]. All these show that the development of China's tourism industry has entered a new stage.

As an initiative of "the Belt and Road" network, China will greet more overseas tourists, which puts higher demands on China's tourism public service system. However, there are still

The project is funded by 2017 “ 10,000 Tourism Talents Program” (No. WMYC201720080) of the National Tourism Administration and Student Innovation and Entrepreneurship Project of the Fujian Normal University (No.cxxl-2018084) numerous inadequacies of the supply capacity in the Chinese tourism market; above all, the existing single and universal tourism public service system cannot meet the characteristics and quality requirements of the people in tourism activities. Therefore, the optimization and upgrading of the service system is imperative.

In recent years, China has attached great importance to the construction of smart tourism cities. The concept, connotation, goals, paths and modes of smart city construction reflect distinct Chinese characteristics respectively. In view of this, the 19th National Congress of the Communist Party of China proposed the idea of building a "smart society." The intelligent tourism public service system is an important part of a smart city, while the smart city is the basic element that constitutes a smart society. The intelligent tourism public service system can promote the construction of smart cities, laying a solid foundation of the realization of smart society sharing.

Nowadays, China has announced a number of "smart tourism pilot cities" in order to promote the construction of smart tourism cities. Among them, the major representative cities like Beijing, Hangzhou, Nanjing and Wuhan have initially built a tourism public service system, including tourism public information service system, tourism security guarantee system, convenient system of tourism transportation, convenient and beneficial system for tourists, and tourism administrative service system.

The modernization of China's industry promotes the wide application of modern information technology such as cloud computing, Internet of Things and big data in the tourism industry, making it easier for people to obtain relevant information at all stages of tourism and facilitating people's travel greatly. The smart tourism public service system is driven by the continuous improvement of science and technology and the increasingly abundant talent pool.

\section{The Study of Tourism Public Service System}

\section{A. The significance of the tourism public service system}

Public service is the provision of public goods and services, including strengthening urban and rural public facilities; 
developing social employment, social security service and utilities such as education, science and technology, culture, health and sports; releasing public information. In this way, it can provide guarantee and create conditions for people in the society to live and participate in economic, political and cultural activities [2].

Tourism public service and public service are coordinated and complementary. On the one hand, tourism public service is the promotion and integration of the special requirements put forward by the existing normal public service; on the other hand, it is a specially provided and targeted public service and product that aim to cope with the specific service objects of tourism [3].

As an important part of social public service, tourism public service should regard tourists as the service objects and follow the method of providing public tourism products and services, hence creating conditions and providing guarantee for tourists' tourism activities.

From the perspective of the construction of new smart tourism cities, the tourism public service system, as the integrated division of the specific content of tourism public service, should be further optimized and upgraded combining with the informative and intelligentized characteristics of intelligent city, hence giving full play to its role in tourism activities.

\section{B. Construction of the tourism public service system}

During the "Twelfth Five-Year Plan" period, China's tourism public service was promoted in an orderly manner, and some fields like tourism public service infrastructure, tourism information consultation, tourism transportation distribution, toilet revolution, convenient and beneficial service system for tourists, and tourism security guarantee were accelerated to develop. The national tourism public service system was initially established [4]. Therefore, this paper believes that the construction of tourism public service system in the context of smart cities should mainly include the following aspects:

\section{1) Tourism information consultation service system}

With the development of the Internet, people's ways of seeking travel information are increasing while the quality of information obtained is uneven and the practicality and authenticity cannot be guaranteed. The false tourism information will seriously affect the tourists' experience. Furthermore, the content of tourism information is rich and diverse, but the utilization rate of information resources is low. The tourism public service providers cannot effectively use information to provide tourists with personalized and highly satisfied services.

\section{2) Convenient service system of tourism transportation}

Convenient tourism transportation is an important driving factor for the development of tourism, and it is more demanding than general transportation in terms of services. The rapid development of self-drive tour leads to an increase in the pressure on tourism public transportation. The existing tourist transportation system can hardly meet the realistic demands with the prominent problems such as travel and parking difficulties.
The real-time information of tourist attractions and roads changes a lot, the updating and feedback abilities of road conditions are poor and the "last mile" problem of tourism is widespread, which cannot provide tourists with a better tourism experience. As an essential facility for implementing transportation management, traffic signs have not been set comprehensively with standardization, greatly reducing the ability to regulate traffic flow and improve road capacity. The "Belt and Road" initiative has brought a large number of international tourists to China; however, the current traffic signs are difficult to meet the diverse international needs, which seriously affect the tourist experience.

\section{3) Tourism security guarantee service system}

At present, China lacks attention to tourism safety, and the tourism security service system is not perfect. As a result, personal safety of tourists can hardly be guaranteed during the tourism process. It not only affects the smooth progress of tourism activities, but also causes some economic losses of tourists, even endangering the personal safety of tourists and affecting the stability and unity of the society. If tourism safety accidents are not dealt timely, it will easily cause adverse social impact, damage the country's tourism reputation and hinder the development of tourism. Therefore, it is of great significance to strengthen tourism safety management.

The rapid development of informatization makes it unavoidable for tourists to disclose personal information various times when coming across problems like sightseeing, accommodation and transportation during the tourism process. However, the construction of China's information security system is relatively late, making it difficult to guarantee the safety of tourism information.

4) Convenient and beneficial service system for tourists

The "Belt and Road" initiative has brought a large number of overseas tourists to China. At the same time, it has put forward higher requirements of China's tourism infrastructure construction so that enjoying safe, efficient and intelligent convenience services of tourists becomes a new development direction. Nowadays, the infrastructure of tourist attractions is not convenient or diversified; some issues are notable like the imperfect construction of communication networks and the imperfect logistics system of tourism products. The existing convenient and beneficial service system for tourists is difficult to meet their needs.

\section{5) Tourism administrative service system}

At present, the development of "the Belt and Road" has brought a new round of international tourism boom to China while the construction of tourism e-government has failed to meet the realistic needs of tourism development, which has increased difficulties of the timely guarantee of tourists' rights and interests in tourism activities. The development of tourism e-government can enhance the transparency of information and transmit relevant information of tourism management departments to tourists through the network, so that the supervision of the tourism-related administrative departments by the public is more convenient and comprehensive.

What's more, the imperfect administrative facilities of tourist destinations make it difficult for the government and 
relevant departments to timely find out the negative impact of tourism activities on tourism resources, which is not conducive to the scientific and rational use of tourism resources.

\section{Intelligent Development Countermeasures of the TOURISM PuBlic SERVICE SySTEM}

In order to promote the construction of China's new smart tourism city, we must actively advance the development of digital China construction from the smart society. It is imperative to optimize and upgrade the tourism public service system.

\section{A. Construction of the tourism public information service system}

The key to the construction of tourism public information service system is to build a tourism public information sharing platform, providing exchange platform for the participants of tourism activities based on information technology, establishing communication channels for government, tourists, tourism enterprises and regional residents, and promoting new smart tourism city construction in all directions.

\section{1) Establish the basic database}

The foundation of tourism public information platform aims to collect tourism information and establish a database. The database provides tourists with more comprehensive information services and collects basic information of tourists, so that the relevant government departments can make new plans according to the needs of tourists and the actual situation. The basic database should collect information including climate, urban profile, tourism resources, traffic information, history and culture, etc. to enhance the tourism experience for tourists, and at the same time gather information such as the origin, age and destination of tourists and the way of travel by tourists, etc. as an important basis for government tourism planning.

\section{2) The construction of information sharing platform}

Under the premise of a complete basic database, the information sharing platform is formally built under the guidance and supervision of the government. Tourism enterprises actively provide information, regional residents make demands, and tourists receive information and improve it. The government provides some information and supervises the sources of information; the tourism enterprises offer most of the information and promote it; the regional residents propose their demands while receiving information; and the tourists use the information to improve the tourism experience and provide feedback. The government accepts appeals and feedbacks and improves tourism public services while tourism enterprises optimize tourism products based on the information platform. The construction of tourism public information platform will enable the four parties to participate in the optimization and upgrading of the tourism public service system and the building of communication channels will properly handle multi-party relations in tourism activities.

\section{3) Apply new information technology and sharing mode}

In the process of building the basic database, the information of tourists is collected by means of face recognition, satellite positioning and other technologies. Adopting big data analysis technology, we screen a large number and a wide variety of tourism information and eliminate the false information. After the comprehensive arrangement and analysis, it will provide a theoretical basis for the upgrading and optimization of the tourism public service system. The information sharing platform is based on the official website with the network self-media, and the application subject of it is smart phone software, transferring the tourism information through the new sharing mode with a wide audience to realize the popularity of tourism public information sharing platform.

4) Building an information service platform--taking Nanjing as an example

As the first pilot city of smart tourism in China, Nanjing has provided the local residents with information services including life, medical care, transportation, tourism, convenience, government affairs, information and affairs handling through the development of the mobile application software "My Nanjing" in the construction of the public service system. Nowadays, "My Nanjing" has become a representative presentation of the construction of China's information sharing platform. In the process of building an information sharing platform, Nanjing makes full use of relevant service resources and authoritative information of relevant government departments and public institutions to improve the level of public services and ensure information sources. The platform relies on the authority and supervision of the government to actively mobilize social resources and provide high-level information services for tourists. Nevertheless, due to lack of communication channels, the platform is impossible to properly handle the relationship between the various parties in the tourism activities and fails to reach the targeted optimization and upgrading purpose of the tourism public service system in Nanjing.

\section{B. Construction of the convenient transportation service} system

In the new era of mass tourism, tourists' demands for convenience, timeliness and mobility of tourism public services are constantly increasing. Traditional tourism public services can hardly meet actual needs and some problems such as difficulty in travel and in parking have long existed in some areas. The convenient transportation service system is indispensable in the building of the new intelligent tourism public service system [5].

1) Enhance informatization infrastructure construction of the tourism

We should promote the application of information technology such as the Internet and cloud computing in touristintensive areas like hotels, tourist attractions, rural tourist spots and transportation hubs; identify the number and characteristics of people and vehicles; realize the dynamic monitoring of tourist hotspots to provide timely and effective tourist traffic information for tourists; realize the barrier-free travel of tourists by planning the optimal travel route on the smart phone platform with reference to the tourist destinations selected by 
tourists; solve the "last mile" issue of tourism; and enhance travel experience.

2) Improve the guidance and identification system of tourism transportation

With the development of "the Belt and Road", the number of international tourists that China receives each year has increased significantly. Therefore, it is necessary to raise the intelligence level of tourism traffic signs according to the different levels of awareness of tourists from all countries, and intelligently mark corresponding scenic spots, hotels and so on to achieve the standard and clear specification of tourism traffic signs that can be identified quickly. At the same time, the regional humanities and tourism characteristics should be added to the logo, and a tourist traffic sign system with urban characteristics is to build [6].

3) Promote the intelligent construction of tourism transportation service--taking Wuhan as an example

As one of the pilot cities of smart tourism in China, Wuhan has initially set up a relatively sound urban transportation convenient service system in the construction of transportation service system. By setting up the intelligent bus electronic stop sign, tourists can directly view the information of the line site, receive the vehicle-to-station forecast, and realize the intelligent bus ride. The intelligent bus station adds relevant probes and the bus dispatcher can dispatch instructions in time according to the bus operation. In this way, they can adjust the driving interval to shorten the waiting time of passengers, greatly improving the operational efficiency of urban public transportation and promoting the construction of regional convenient transportation service system.

\section{Intelligent security guarantee}

The tourism security guarantee is a key issue in the development of tourism. Confronting with the frequent occurrence of multi-country tourism violence, it is of great significance to shape the image of a good tourism country by building a sound and efficient tourism safety guarantee mechanism to protect the safety of tourists' lives and property.

\section{1) Improve emergency measures for safety accidents}

In view of the emergencies such as sudden illnesses and accidental injuries during the tourism process, China has not yet established a comprehensive tourism intelligent medical system and only adopts methods such as registration and reporting of tourists' sudden illnesses. The actual effect is not ideal because of inadequacies of police and medical resources. Therefore, in the process of building a tourism intelligent medical system, smart medical equipment can be added to directly monitor the physiological condition of the patient so that the medical staff can make judgments remotely and guide the on-site personnel to carry out first aid.

In recent years, various regions of China have adjusted measures to local conditions and have carried out numerous practical work innovatively in order to promote the construction of an intelligent security mechanism. In the construction of tourism police in Sanya, Hainan Province, China, it has set up a tourism police service platform to provide timely and efficient consulting services and emergency assistance for tourists while continuously improving the quality of and enriching the skills of police services, hence shaping a tourism police brand with regional characteristics. In Hainan, China, it has set up the first tourism circuit court in China for the large turnover of Sanya's international tourist destinations and numerous tourist disputes. The court enjoys multi-sector coordination and the linkage mechanism. After receiving complaints from the parties, it reviewed and implemented problems quickly, achieving a tour when handling the case. In the future, the scenic spot can achieve the global and dynamic nature of the tourism security guarantee by setting up a tourism police, a tourism circuit, a tourist intelligent navigation mechanism, a joint law-related working mechanism of the law enforcement department, and a global tourism linkage mechanism.

\section{2) Safeguard information security of tourists}

In the informatization society, information security has received more concerns internationally. Tourists have hidden dangers of leaking personal information when registering new accounts, connecting free $\mathrm{Wi}-\mathrm{Fi}$, participating in tourism activities and so forth and tourism information security can hardly be guaranteed. However, due to imperfect laws and regulations, the information security mechanism has not been implemented. China must learn from developed countries in terms of information security and increase the protection of personal privacy.

\section{Construction of the convenient and beneficial system for tourists}

With the continuous advancement of a well-off society in an all-round way and the improvement of residents' living standards, the rise of a new round of "tourism fever" has put forward new requirements for the construction of tourist destination infrastructure and reception facilities. It is extremely urgent to promote the convenience and diversification of tourism infrastructure and build a smart and convenient service system for tourists.

\section{1) Improve the tourism logistics system}

We are supposed to accelerate the construction of professional Internet of Things infrastructure, establish a unified tourism commodity logistics and transportation system and guide all kinds of Internet platforms and market entities to enter in order. In this way, we can provide more convenient logistics services for tourists' leisure shopping and meet the individual needs of tourists. Furthermore, we need to provide a new reference for improving the convenient and beneficial system and further improve the quality of tourism services.

\section{2) Advance the full coverage of the communication} network

In terms of communication network construction, we will promote the construction of communication infrastructure in transportation hubs such as transportation hubs, tourist attractions, tourist resorts and rural tourist spots, realizing full coverage of WiFi to meet the network needs of tourists in the tourist destination activity area and effectively avoid the lack of signal in some areas and the situation that tourists cannot use the network equipment. Previously, Hangzhou, China also actively guided tourism companies such as hotels and scenic 
spots to open WiFi wireless networks on the basis of the promotion of the "i-hangzhou" wireless coverage project in the smart city, further improving the construction of communication networks and building a convenient and efficient public network service system. It can be used as a reference for the intelligent construction of the tourism public service system in other smart tourist cities in China.

\section{3) Enhance tourism consumption facilitation}

At this stage, the use of urban card and tourist card in various regions of China has gradually become popular. At present, the use of cards in most cities is limited to public transportation, and there is no organic connection between urban transportation and tourist attractions. In 2013, Hangzhou issued the "Tourism Consumption Card through All Hangzhou", which allowed tourists to take subway and public transportation, rent city bicycles, purchase scenic spots, book hotels and use other functions during the tour, while tourists can enjoy discounts during the purchase of special products and souvenirs. In the future, cities in China can plan the tourism resources in the region and promote the use of regional tourism consumption cards in the process of building tourism services, realizing the full coverage of tourism public services in terms of space, time, function, social groups and so on.

\section{E. Construction of intelligent administrative service}

Building intelligent tourism administrative services is an important part of the construction of new smart tourism cities. Comprehensive and efficient tourism administrative services can shape the good image of a great tourism country and promote the steady development of China's tourism industry.

\section{1) Personalized e-government construction}

The model innovation of E-government and service provision must be based on the needs of the public so as to improve the efficiency of service use [7]. As a representative presentation of the construction of smart cities in Nanjing, the application software "My Nanjing" integrates the service resources and authoritative information of relevant government departments such as transportation, culture and tourism to provide high-quality information services for Nanjing residents and improve the convenience of their lives, hence promoting the construction development of e-government in Nanjing. The platform needs to be registered with the personal information of Nanjing residents, which ensures authenticity of the user information to a certain extent. Nevertheless, it also limits the use rights of foreign tourists, which is not conducive to its application in smart tourism and it is difficult to meet the needs of development of smart tourism city.

The "Belt and Road" initiative will bring a large number of inbound tourists to China. In response to changes of the structure of tourists and needs of tourists, China's tourism egovernment construction should move towards internationalization, including building online service points for inbound tourists and intelligent identification as well as endeavoring to perfect the intelligent international tourism industry norms.

\section{2) Supervision of the intelligent tourism scenic areas}

The supervision of tourist attractions plays an important role in shaping the image of urban tourism, protecting tourism resources and promoting the sustainable development of tourism. The scenic spot uses the intelligent monitoring system to monitor the uncivilized behavior of tourists and write it down in the integrity file and handle it according to the regulations of the scenic spot; the relevant departments use the instant information feedback system to monitor the bad behavior of the operators and merchants in the scenic spot and count them into the integrity file, and then cope with it according to laws and regulations; an intelligent environmental monitoring system is applied to detect the natural environment of the tourist destination in real time, and the tourism destination is immediately rectified if the critical value is approached. Through intelligent supervision, we try to guide tourists, tourist attractions and other groups to regulate tourism behaviors and protect rights and interests of multiple parties, laying a solid foundation for the standardized development of urban tourism.

\section{CONCLUSION}

Through studying the intelligent upgrading of the tourism public service system, the paper provides development strategies for the optimization and upgrading of China's tourism public service system, hence promoting the construction of China's new smart tourism city and creating the image of a new international smart tourism giant by combining China's important position in "the Belt and Road" concept, addressing the inadequacies of China's tourism development and guiding by the idea of promoting tourism information service, tourism security guarantee, tourism transportation service, convenient and beneficial service for tourists and the intelligent development of the tourism administrative system.

\section{REFERENCES}

[1] China Tourism Academy. Annual Report of China Inbound Tourism Development [R].2018.

[2] Wen Jiabao. Report on the Work of the Government [R].2010.

[3] Li Shuang. Tourism Public Service: Connotation, Characteristics and Classification Framework [J]. Tourism Tribune. 2010, 25(4): 20-26.

[4] China National Tourism Administration. National Tourism Public Service Planning during "13th Five-Year Plan” [R].2017.

[5] Li Junpeng. Accelerating the Improvement of Touris m Public Service System [J]. Tourism Tribune. 2012, 27 (1): 4-6.

[6] Li Bingyi. Construction of Urban Tourism Public Service System [J].Urban Tourism.2013, 20(1):98-102.

[7] Wang Peng. Liu Yanchen. Characteristics and Trends of China's EGovernment Development in the Age of "Internet Plus" [J]. Journal of Hunan University of Technology (Social Science Edition).2017, 22(3): 63-66. 